\title{
Hipersegregação das elites metropolitanas brasileiras na década de 2000: interpretações a partir da Região Metropolitana de Belo Horizonte
}

Hypersegregation of the Brazilian metropolitan elites in the 2000s: interpretations based on the Belo Horizonte Metropolitan Region

Jupira Gomes de Mendonça [l] Luciana Teixeira de Andrade [II] Alexandre Magno Alves Diniz [III]

\section{Resumo}

Este artigo apresenta alguns resultados da comparação da estrutura socioespacial das 15 principais regiões metropolitanas brasileiras e de sua evolução no período entre 2000 e 2010. A análise aborda prioritariamente o fenômeno de concentração dos grupos de mais alto status nos espaços superiores dessas metrópoles, configurando a sua hipersegregação. Hipóteses explicativas para esse processo são apresentadas a partir da análise específica da Região Metropolitana de Belo Horizonte, cuja composição social é muito próxima da composição média das 15 RMs estudadas e para a qual há dados específicos sobre dinâmica imobiliária, índice de qualidade de vida e mobilidade residencial. A histórica atratividade das áreas centrais intensificou-se na década de 2000, mantendo-as como localização preferencial dos investimentos imobiliários de alto padrão.

Palavras-chave: estrutura socioespacial; hipersegregação; áreas centrais; dinâmica imobiliária; metrópoles brasileiras.

\begin{abstract}
This article presents some results of the comparison of the socio-spatial structure of the 15 main metropolitan regions of Brazil and their evolution between 2000 and 2010. The analysis focuses primarily on the concentration of high status groups in the so-called "upper spaces" of these metropolises, leading to their hypersegregation. Explanatory hypotheses for this process are produced through the specific analysis of the Belo Horizonte Metropolitan Region, whose social composition is very close to the average composition of the 15 studied metropolitan regions and for which there are specific data on real estate dynamics, quality of life index and residential mobility. The historic attractiveness of the central areas was intensified during the 2000s, maintaining them as the preferred location for high-quality real estate investments.
\end{abstract}

Keywords: socio-spatial structure; hypersegregation; central areas; real estate dynamics; Brazilian metropolises. 
A análise da distribuição dos grupos sociais no espaço metropolitano de 15 metrópoles brasileiras na última década mostra dois fenômenos comuns. 0 primeiro deles, que já vinha sendo observado desse os anos de 1980, diz respeito ao espraiamento dos grupos médios pelas periferias metropolitanas, em especial nas chamadas periferias consolidadas, ou seja, aquelas com melhor infraestrutura urbana (Caldeira, 2000; Ribeiro, 2002; Mendonça e Costa, 2011; Lago, 2011). 0 segundo, que se manifestou de forma geral e mais intensa nesta última década, é a maior concentração dos grupos de alto status nos espaços superiores dessas 15 metrópoles. Dada a novidade deste último fenômeno, optamos por priorizá-lo neste artigo. No entanto, por ser a segregação relacional, o espraiamento dos grupos médios pelas metrópoles, como será mostrado a seguir, está entre os movimentos que ajudam na compreensão da maior segregação das elites, ou hipersegregação, como esse fenômeno será aqui denominado.

0 conceito de hipersegregação é atribuído a Massey e Denton (1989) que o utilizaram para descrever a alta segregação dos afro-americanos em espaços metropolitanos norte-americanos nas cinco dimensões por eles estudadas: uniformidade, exposição, agrupamento, concentração e centralização. Essa situação não se repetia, entretanto, com os hispânicos, o que mostrava quão única e distinta era a segregação espacial dos afro-americanos. Neste artigo, o conceito de hipersegregação será utilizado para qualificar a alta concentração dos grupos de mais alto status nas áreas centrais das metrópoles brasileiras. 0 uso deste conceito tem como objetivo mostrar o aumento da segregação espacial desse grupo social nas
15 regiões metropolitanas analisadas. Mostra, ainda, que, apesar da autossegregação ou segregação voluntária de parcela dos grupos de alto status socioeconômico nos chamados condomínios fechados, a porção das metrópoles com maior concentração numérica e relativa desse grupo continua a ser as áreas centrais das cidades-polo.

Se a constatação da hipersegregação já é em si um fato relevante, mais importante seria compreender como e por que isso ocorreu. No entanto, identificar os fenômenos relacionados à segregação não é algo simples, até porque ela é resultado de uma combinação de vários fatores. $E$, em se tratando de 15 regiões metropolitanas, seria muito difícil encontrar dados nacionais produzidos, com uma mesma metodologia, sobre as dinâmicas associadas à segregação mais discutidas pela literatura, tais como: políticas urbanas, mercados imobiliários, concentração de bens raros (Bourdieu, 1997) e/ou amenidades urbanas (Clark et al., 2002). Por essa razão, vamos abordar incialmente a dimensão nacional do fenômeno da hipersegregação, mas as tentativas de compreensão serão feitas para uma única metrópole, Belo Horizonte, em função da existência de significativo número de estudos anteriores sobre a RM, bem como da disponibilidade de dados necessários à caracterização dos processos segregativos em escala intraurbana. Além disso, Belo Horizonte é a metrópole cuja composição social mais se aproxima daquela encontrada para o conjunto metropolitano estudado (Diniz et al., 2018), sendo os seus resultados sugestivos de processos mais gerais, que poderão servir como referência para o exame da hipersegregação em outras metrópoles. 
Este artigo está estruturado em três partes. A primeira parte apresenta a metodologia de estudo das 15 metrópoles. A segunda traz os resultados mais gerais encontrados, com destaque para a hipersegregação presente nas 15 metrópoles. Na terceira parte, esse fenômeno é analisado especificamente para a Região Metropolitana de Belo Horizonte.

\section{Metodologia}

Durante quase 20 anos o Observatório das Metrópoles analisou a dinâmica das metrópoles brasileiras, a partir de uma metodologia comum, com o objetivo de verificar a distribuição dos grupos sociais no território. A construção dessa metodologia teve como ponto de partida a centralidade do trabalho na sociedade brasileira. Desse modo, utilizando-se de uma base de dados comum a todas as metrópoles, a variável ocupação dos censos demográficos foi usada, com filtros de renda, escolaridade e posição na ocupação, para a construção de uma hierarquia que representasse as posições na sociedade brasileira (ver Quadro 1).

A verificação da distribuição dos diversos grupos sociais no território metropolitano foi feita por meio de técnicas de análise fatorial por correspondência binária e de classificação hierárquica ascendente, encontrando unidades espaciais caracterizadas por forte homogeneidade interna e diferenciação externa, permitindo a criação de uma tipologia socioespacial. Esse procedimento permitiu análises da estrutura socioespacial de cada uma das metrópoles e a verificação de processos de maior e/ou menor segregação residencial. ${ }^{1}$

Neste texto, a segregação é compreendida como expressão das desigualdades sócio-ocupacionais no espaço, ainda que não se trate de um simples reflexo. As regras da ordem espacial relacionam-se com o poder econômico e social dos grupos, mas também com processos históricos que ficam inscritos nas estruturas construídas. Segregação indica, portanto, separação de grupos sociais no espaço, de modo que, por um lado, quanto mais socialmente homogêneo for um recorte espacial, mais segregado ele será; por outro lado, quanto mais heterogêneo for o espaço, menos segregado ou mais mesclado socialmente ele será.

0 estudo desse fenômeno é realizado com base na observação da maior presença de um ou mais grupos sócio-ocupacionais nos espaços, uma vez que esses recortes espaciais não são ocupados exclusivamente por membros de um único grupo sócio-ocupacional. Os resultados mostram a preponderância, mas não a exclusividade, de um ou dois grupos sobre outros. Em se tratando do Brasil, mas também da América Latina, a forma dominante de segregação espacial encontra-se associada aos estratos sócio-ocupacionais, ou seja, à segregação por classe social.

Entre os seus efeitos, um dos principais é a reprodução das desigualdades. Residir em um determinado espaço, mais ou menos segregado, está diretamente relacionado com as oportunidades de vida (Bourdieu, 1997; Ribeiro, 2003; Villaça, 1998), ou seja, a população não se beneficia de forma homogênea dos recursos urbanos. A sua maior ou menor acessibilidade vai compor o que Harvey (1977) chamou de renda real. 


\section{Quadro 1 - Categorias Sócio-ocupacionais}

\begin{tabular}{|c|c|}
\hline Dirigentes & $\begin{array}{l}\text { Grandes Empregadores } \\
\text { Dirigentes do Setor Público } \\
\text { Dirigentes do Setor Privado }\end{array}$ \\
\hline Pequenos Empregadores & Pequenos empregadores \\
\hline Ocupações de Nível Superior & $\begin{array}{l}\text { Profissionais Autônomos de Nível Superior } \\
\text { Profissionais Empregados de Nível Superior } \\
\text { Profissionais Estatutários de Nível Superior } \\
\text { Professores de Nível Superior }\end{array}$ \\
\hline Ocupações Médias & $\begin{array}{l}\text { Ocupações Artísticas, Artesãos e Similares } \\
\text { Ocupações de Escritório } \\
\text { Ocupações de Supervisão } \\
\text { Ocupações Técnicas } \\
\text { Ocupações Médias da Saúde e Educação } \\
\text { Ocupações de Segurança Pública, Justiça e Correios }\end{array}$ \\
\hline Ocupações do Terciário & $\begin{array}{l}\text { Trabalhadores do Comércio } \\
\text { Prestadores de Serviços Especializados }\end{array}$ \\
\hline Ocupações da Indústria & $\begin{array}{l}\text { Trabalhadores da Indústria Moderna } \\
\text { Trabalhadores da Indústria Tradicional } \\
\text { Operários dos Serviços Auxiliares } \\
\text { Operários da Construção Civil }\end{array}$ \\
\hline Ocupações no Terciário Não Especializado & $\begin{array}{l}\text { Prestadores de Serviços Não Especializados } \\
\text { Trabalhadores Domésticos } \\
\text { Ambulantes e biscateiros }\end{array}$ \\
\hline Ocupações Agrícolas & Agricultores \\
\hline
\end{tabular}

Nos estudos empíricos realizados pela rede Observatório das Metrópoles, a comparação da tipologia socioespacial encontrada em cada década não só permitiu a análise sobre a segregação, mas também a observação de retratos da realidade, cuja compreensão demanda outros estudos sobre as dinâmicas de estruturação do espaço urbano e metropolitano, os diversos tipos de intervenção estatal, a dinâmica de promoção imobiliária e os impactos da reestruturação produtiva, entre outros.
Assim, a construção de tipologias socioespaciais específicas foi realizada em cada metrópole, pelas equipes locais do Observatório das Metrópoles, com base em um método comum. ${ }^{2}$ No entanto, esse método é relacional, isto é, compara a composição social de cada unidade espacial com todas as demais, agrupando aquelas com composição semelhante entre si e diferentes das demais, dentro de cada região metropolitana. Esse aspecto limita significativamente a possibilidade de se empreenderem 
comparações entre os resultados de diferentes RM, embora algumas análises comparativas tenham sido elaboradas anteriormente (Lago e Mammarella, 2010; Ribeiro e Lago, 1992; Ribeiro, Costa e Ribeiro, 2013).

0 presente estudo supera essa limitação, ao realizar a construção de uma tipologia que relacionou, em um só procedimento, todas as unidades espaciais e as categorias sócio-ocupacionais das 15 principais regiões metropolitanas brasileiras. ${ }^{3} 0$ resultado para cada região metropolitana, portanto, deve ser compreendido na sua relação com o conjunto das 15 metrópoles estudadas, fato que permite comparações entre as RM analisadas. Essa construção foi feita considerando-se as Áreas de Ponderação (AP) definidas pelo IBGE para o ano de 2000 e para o ano de 2010 separadamente. ${ }^{4}$ A delimitação das AP em 2000 é diferente daquela de 2010 e, por isso, a comparação temporal deve ser feita com cautela, não sendo possível a comparação par-a-par. ${ }^{5}$

Outra observação importante a ser feita é que a categoria dos trabalhadores agrícolas foi retirada dos procedimentos metodológi$\cos$, tendo em vista que esta é uma categoria que representa apenas $1,7 \%$ e $1,8 \%$, respectivamente em 2000 e em 2010, do total da população ocupada das 15 regiões metropolitanas brasileiras estudadas. ${ }^{6}$ Além disso, estamos aqui tratando da dinâmica metropolitana (um estágio avançado em relação aos processos de urbanização), e as ocupações agrícolas, além de numericamente pouco expressivas, tendem a diminuir ainda mais no conjunto e na dinâmica urbana, permanecendo apenas algumas ilhas de ruralidade (Lefebvre, 1969). Deste modo, a nosso ver, a retirada dessa categoria permite verificar de forma mais consistente a composição social nos diversos espaços urbanos.

\section{Hipersegregação das áreas centrais e mistura social nas periferias}

A construção das tipologias socioespaciais para o conjunto das 15 metrópoles brasileiras estudadas resultou em sete tipos para 2000 e nove tipos para 2010. A primeira observação decorrente desse resultado é que a estrutura socioespacial metropolitana brasileira ficou mais complexa, com espaços mais heterogêneos, evidenciando o espraiamento de grupos médios e parte dos superiores no território, com o surgimento dos tipos Heterogêneo-Superior e Heterogêneo-Médio. ${ }^{7}$

Ao mesmo tempo, os espaços do tipo Superior ficaram mais exclusivos, com maior concentração de dirigentes e profissionais de nível superior e menor participação de todos os trabalhadores em ocupações manuais e da maior parcela das ocupações médias. ${ }^{8}$ Alguns estudos da dinâmica imobiliária explicam processos relacionados a esse movimento, como será mostrado mais adiante.

A Tabela 1 permite observar a maior ou menor concentração das categorias sócioocupacionais em cada tipo, em 2000, por meio do Quociente Locacional, e a Tabela 2 permite a observação para o ano de $2010 .{ }^{9}$ As cores nas tabelas ajudam a visualizar as categorias que se encontram super-representadas (azul), sub-representadas (rosa) e aquelas cuja representação se aproxima da média do conjunto metropolitano (amarela). 
Tabela 1 - Tipos socioespaciais e quociente locacional das categorias sócio-ocupacionais - Brasil - 2000

\begin{tabular}{|c|c|c|c|c|c|c|c|}
\hline Tipo 2000 & 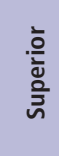 & 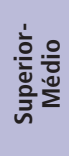 & 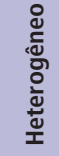 & 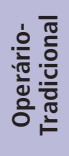 & $\begin{array}{l}\frac{\dot{0}}{\frac{\pi}{2}} \\
\frac{\pi}{\frac{\pi}{2}} \frac{0}{0} \\
\text { 응 }\end{array}$ & 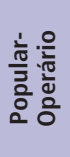 & $\frac{\frac{1}{5}}{\frac{0}{0}}$ \\
\hline Grandes Empregadores & 4,5 & 1,2 & 0,6 & 1,0 & 0,4 & 0,3 & 0,3 \\
\hline Dirigentes do Setor Público & 3,0 & 1,5 & 0,7 & 0,5 & 0,5 & 0,5 & 0,5 \\
\hline Dirigentes do Setor Privado & 5,5 & 1,2 & 0,5 & 0,3 & 0,1 & 0,2 & 0,1 \\
\hline Profissionais Autônomos de Nível Superior & 4,1 & 1,3 & 0,6 & 0,2 & 0,3 & 0,4 & 0,3 \\
\hline Profissionais Empregados de Nível Superior & 3,6 & 1,5 & 0,7 & 0,3 & 0,3 & 0,4 & 0,2 \\
\hline Profissionais Estatutários de Nível Superior & 3,6 & 1,7 & 0,6 & 0,1 & 0,2 & 0,3 & 0,2 \\
\hline Professores de Nível Superior & 2,6 & 1,7 & 0,8 & 0,2 & 0,4 & 0,4 & 0,3 \\
\hline Pequenos Empregadores & 2,7 & 1,3 & 0,9 & 1,0 & 0,6 & 0,5 & 0,5 \\
\hline Ocupações Artísticas, Artesãos e Similares & 1,8 & 1,2 & 0,9 & 0,9 & 1,0 & 0,7 & 0,6 \\
\hline Ocupações de Escritório & 1,0 & 1,4 & 1,2 & 0,6 & 0,7 & 0,8 & 0,5 \\
\hline Ocupações de Supervisão & 1,5 & 1,3 & 1,1 & 1,0 & 0,8 & 0,7 & 0,6 \\
\hline Ocupações Técnicas & 1,4 & 1,4 & 1,1 & 0,8 & 0,7 & 0,7 & 0,4 \\
\hline Ocupações Médias da Saúde e Educação & 0,8 & 1,3 & 1,1 & 0,6 & 0,8 & 1,0 & 0,7 \\
\hline Ocupações de Segurança Pública, Justiça e Correios & 1,0 & 1,6 & 0,9 & 0,3 & 0,6 & 0,9 & 0,6 \\
\hline Trabalhadores do Comércio & 0,6 & 1,0 & 1,1 & 0,6 & 1,0 & 1,1 & 0,9 \\
\hline Prestadores de Serviços Especializados & 0,5 & 0,9 & 1,0 & 0,5 & 1,0 & 1,2 & 1,2 \\
\hline Trabalhadores da Indústria Moderna & 0,2 & 0,6 & 1,3 & 1,1 & 1,7 & 1,1 & 0,9 \\
\hline Trabalhadores da Indústria Tradicional & 0,3 & 0,6 & 1,1 & 7,8 & 2,2 & 1,0 & 0,8 \\
\hline Operários dos Serviços Auxiliares & 0,3 & 0,7 & 1,2 & 0,7 & 1,4 & 1,2 & 1,0 \\
\hline Operários da Construção Civil & 0,2 & 0,5 & 0,8 & 0,9 & 1,2 & 1,5 & 2,1 \\
\hline Prestadores de Serviços Não Especializados & 0,4 & 0,7 & 0,9 & 0,5 & 1,1 & 1,4 & 1,6 \\
\hline Trabalhadores Domésticos & 0,8 & 0,7 & 0,7 & 0,5 & 0,9 & 1,3 & 2,1 \\
\hline Ambulantes e biscateiros & 0,4 & 0,9 & 1,0 & 0,4 & 1,1 & 1,2 & 1,1 \\
\hline
\end{tabular}

Fonte: IBGE (2003), Censo Demográfico de 2000 - dados elaborados. 
Tabela 2 - Tipos socioespaciais e quociente locacional das categorias sócio-ocupacionais - Brasil - 2010

\begin{tabular}{|c|c|c|c|c|c|c|c|c|c|}
\hline Tipo 2010 & 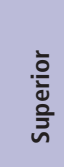 & 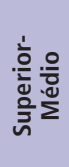 & 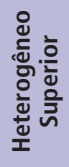 & 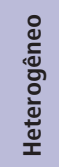 & 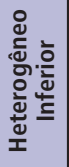 & 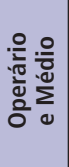 & 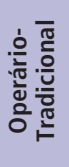 & $\begin{array}{l}\text { 浐 } \\
\frac{\pi}{\frac{\pi}{2}} \\
\frac{0}{0} \\
\frac{0}{0}\end{array}$ & $\begin{array}{l}\frac{\overline{0}}{\overline{2}} \\
\frac{0}{0} \\
\frac{0}{2}\end{array}$ \\
\hline Grandes Empregadores & 6,0 & 3,1 & 0,6 & 1,0 & 0,6 & 0,5 & 0,6 & 0,5 & 0,3 \\
\hline Dirigentes do Setor Público & 3,8 & 3,0 & 1,1 & 0,7 & 0,7 & 0,5 & 0,3 & 0,5 & 0,4 \\
\hline Dirigentes do Setor Privado & 10,7 & 3,7 & 0,4 & 0,6 & 0,3 & 0,2 & 0,7 & 0,3 & 0,1 \\
\hline Profissionais Autônomos de Nível Superior & 5,4 & 3,1 & 0,8 & 1,1 & 0,6 & 0,4 & 0,3 & 0,3 & 0,2 \\
\hline Profissionais Empregados de Nível Superior & 3,7 & 2,7 & 1,0 & 1,3 & 0,6 & 0,6 & 0,3 & 0,4 & 0,3 \\
\hline Profissionais Estatutários de Nível Superior & 3,1 & 3,6 & 1,5 & 0,6 & 0,6 & 0,3 & 0,2 & 0,2 & 0,3 \\
\hline Professores de Nível Superior & 2,0 & 2,1 & 1,3 & 1,2 & 0,8 & 0,7 & 0,5 & 0,5 & 0,5 \\
\hline Pequenos Empregadores & 3,3 & 2,3 & 0,9 & 1,2 & 0,7 & 0,7 & 0,8 & 0,6 & 0,4 \\
\hline Ocupações Artísticas, Artesãos e Similares & 2,0 & 1,5 & 1,1 & 1,0 & 0,9 & 0,8 & 1,5 & 0,7 & 0,8 \\
\hline Ocupações de Escritório & 0,6 & 1,0 & 1,3 & 1,3 & 1,0 & 1,1 & 0,7 & 0,8 & 0,7 \\
\hline Ocupações de Supervisão & 1,7 & 1,7 & 1,0 & 1,3 & 0,9 & 0,9 & 0,7 & 0,7 & 0,6 \\
\hline Ocupações Técnicas & 1,2 & 1,4 & 1,2 & 1,4 & 0,9 & 0,9 & 0,7 & 0,7 & 0,6 \\
\hline Ocupações Médias da Saúde e Educação & 0,6 & 0,9 & 1,3 & 1,0 & 1,1 & 1,0 & 0,7 & 0,8 & 0,9 \\
\hline Ocupações de Segurança Pública, Justiça e Correios & 1,0 & 1,4 & 1,8 & 0,8 & 1,0 & 0,6 & 0,4 & 0,4 & 0,8 \\
\hline Trabalhadores do Comércio & 0,3 & 0,6 & 1,1 & 1,0 & 1,1 & 1,1 & 0,9 & 1,0 & 1,1 \\
\hline Prestadores de Serviços Especializados & 0,3 & 0,5 & 1,1 & 0,8 & 1,2 & 1,0 & 0,8 & 1,0 & 1,3 \\
\hline Trabalhadores da Indústria Moderna & 0,1 & 0,3 & 0,7 & 1,1 & 1,0 & 1,6 & 1,2 & 1,6 & 0,9 \\
\hline Trabalhadores da Indústria Tradicional & 0,1 & 0,4 & 0,7 & 1,1 & 0,8 & 1,6 & 4,4 & 1,3 & 0,8 \\
\hline Operários dos Serviços Auxiliares & 0,1 & 0,3 & 0,8 & 1,0 & 1,0 & 1,4 & 1,9 & 1,5 & 1,0 \\
\hline Operários da Construção Civil & 0,1 & 0,3 & 0,7 & 0,5 & 1,2 & 1,0 & 1,2 & 1,5 & 1,8 \\
\hline Prestadores de Serviços Não Especializados & 0,3 & 0,5 & 0,8 & 0,7 & 1,2 & 1,1 & 0,9 & 1,4 & 1,4 \\
\hline Trabalhadores Domésticos & 0,7 & 0,6 & 0,8 & 0,6 & 1,2 & 0,8 & 0,8 & 1,2 & 1,7 \\
\hline Ambulantes e biscateiros & 0,2 & 0,4 & 1,0 & 0,6 & 1,2 & 1,0 & 1,1 & 1,2 & 1,3 \\
\hline
\end{tabular}

Fonte: IBGE (2011), Censo Demográfico de 2010 - dados elaborados 
Observa-se, também, o espraiamento territorial dos operários, com o surgimento do tipo Operário-Médio, no qual os operários estão mesclados com trabalhadores de ocupações médias. Significativo desse processo é o desaparecimento do tipo Popular-Operário e o surgimento do tipo Operário-Popular, no qual há significativa concentração de categorias mais precarizadas, mas com representação ainda maior de operários da indústria. Em algumas poucas metrópoles permanecem espaços marcadamente operários, com destaque para Fortaleza e Porto Alegre.

No caso dos espaços Superiores, quando se comparam as duas décadas, o que se observa é a maior concentração dos grupos no topo da hierarquia e a menor concentração dos grupos de mais baixo status, o que é indicativo do fenômeno da hipersegregação. Ou seja, os grupos superiores passaram a ocupar o espaço de forma mais exclusiva, tornando-os mais homogêneos e, portanto, mais segregados, durante a década de 2000.

A contraface desse processo, que resultou da saída dos grupos menos privilegiados, incluindo aí parcelas mais baixas dos grupos médios, foi o espraiamento desses grupos por outros espaços das metrópoles, contribuindo para a maior heterogeneidade dos espaços pericentrais e periféricos. No caso da Região Metropolitana de Belo Horizonte (RMBH), segundo Pesquisa de Origem e Destino, ${ }^{10}$ o percentual das pessoas com curso superior que se mudaram para espaços superiores, incluindo os que mudaram dentro desses mesmos espaços (55\%), é maior do que em relação àqueles de mesmo grau de escolaridade que saíram para outros espaços (41\%). Ao contrário, entre as pessoas com ensino médio completo, 0 percentual dos que saíram $(17,4 \%)$ é maior do que aqueles que estavam vindo de outros espaços (15,8\%). ${ }^{11}$ Em geral, os fluxos são de curta distância, mas os que tinham pós-graduação foram para áreas imediatamente periféricas aos espaços superiores, além das áreas dos condomínios nos municípios de Nova Lima e Rio Acima, enquanto, para os que tinham ensino médio completo e saíram, os destinos principais foram áreas da capital um pouco mais distantes, além de uma área em Nova Lima e do centro de lbirité.

\section{Hipersegregação na Região Metropolitana de Belo Horizonte}

Como anunciado no início deste artigo, vamos nos concentrar, a partir deste momento, no fenômeno da hipersegregação, que atinge o conjunto das 15 principais metrópoles brasileiras, tomando como exemplo o caso na RMBH. $\mathrm{Na}$ verdade, por ser o nosso foco as áreas do tipo superior, todas elas localizadas no município-polo, Belo Horizonte, trataremos aqui mais da metrópole do que da RMBH, como será mostrado a seguir.

Como visto, nos espaços classificados como Superiores, a proporção dos grupos dirigentes e profissionais e de nível superior ampliou-se na década, ao contrário dos trabalhadores manuais. Na RMBH, a participação dos dirigentes e ocupados em profissões de nível superior nos espaços de tipo Superior subiu de 41,3\% para 53,6\% entre 2000 e 2010 . 
Os trabalhadores manuais, ao contrário, passaram de $23,2 \%$ para $13,7 \%$ do total da população ocupada nesses espaços, no período.

Na Figura 1, é possível verificar a classificação dos espaços na RMBH. Os espaços Superiores são aqueles em azul mais escuro. A segunda tonalidade de azul mostra os espaços classificados como Superior-Médio; são espaços nos quais ainda há certa concentração dos grupos superiores na hierarquia social (36\% da população ocupada em 2010), mas a participação dos trabalhadores não manuais de nível médio é maior do que nos espaços superiores ( $42 \%$ da População Ocupada (PO), em 2010, nesses espaços, e 36\% da PO nos espaços superiores). Não é possível a comparação

Figura 1 - Estrutura socioespacial da RMBH - 2000 e 2010
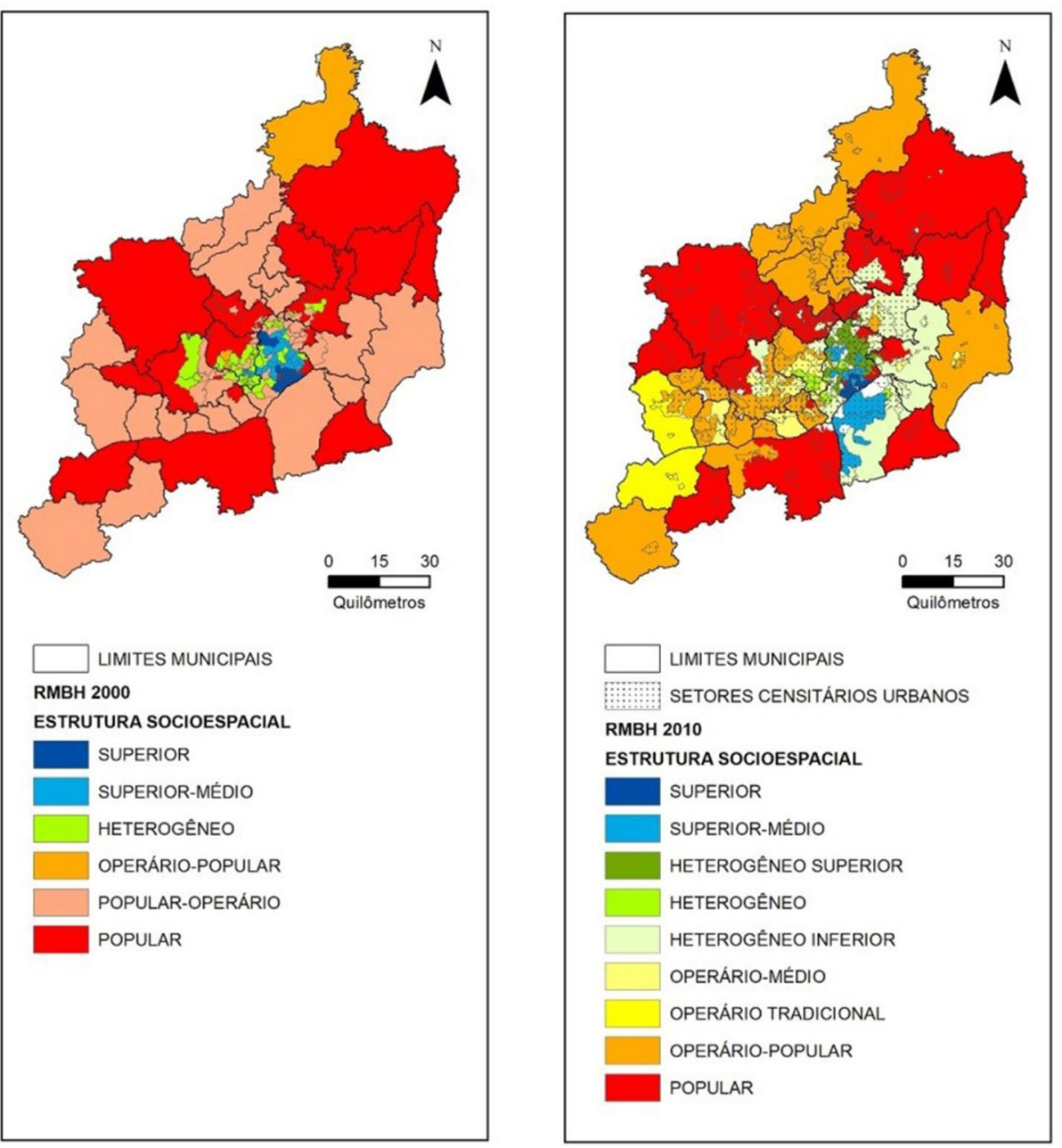
par-a-par, dado que o desenho das áreas de ponderação mudou muito entre um ano e outro. Entretanto, é possível observar, em primeiro lugar, que, em ambos os momentos, esses espaços estão mais concentrados no município-polo. Para 2010, o número de áreas de ponderação no município de Nova Lima, a sul de Belo Horizonte, é maior, permitindo visualizar as áreas dos chamados condomínios fechados, enclaves residenciais para onde vem se dirigindo parte dos grupos superiores. A figura mostra, também, mudanças na região da Pampulha, a norte da área central de Belo Horizonte, com classificação socioespacial descendente.

0 chamado complexo da Pampulha foi obra do prefeito Juscelino Kubitschek na década de 1940, que contratou o arquiteto Oscar Niemayer e o paisagista Burle Marx, para criar, na então pouco habitada região norte da cidade, um complexo residencial, de lazer e turístico da cidade. A partir da década de 1950, ali foi se concentrando um conjunto de moradias dos estratos médios e altos. A alteração descendente na classificação da região da Pampulha não pode ser afirmada pela figura, dadas as diferenças na delimitação das áreas de ponderação, como mencionado. No entanto, trabalho de Macedo e Umbelino (2016) mostra que a região apresentava menor renda em 2010 do que em 2000, o que nos permite afirmar a hipótese da mudança descendente na área. Também, se olharmos a produção imobiliária, 70\% dos apartamentos localizados nessa região foram construídos a partir de 2000. Destes, $71 \%$ são de padrão P3, isto é, padrão médio.

Outro aspecto que nos parece relevante discutir é a comparação entre a composição absoluta e relativa dos grupos sociais nos espaços centrais e dos condomínios, já que nestes também há certa concentração de grupos superiores na hierarquia social. 0 fenômeno dos condomínios expandiu-se em muitas metrópoles brasileiras, a partir dos anos 1980, e foi muito discutido pela literatura, seja porque se tratava de um movimento sem precedentes na segregação metropolitana brasileira, seja porque a forma ostentatória como esses grupos ocupavam e privatizavam o espaço chamou a atenção de muitos estudiosos. Um dos efeitos dessa atenção foi a impressão de que a moradia dos grupos de maior status teria se deslocado das áreas centrais para os condomínios. No caso da RMBH, Nova Lima foi descrita com a cidade dos ricos e dos condomínios, e essa interpretação passou a fazer parte das representações correntes na metrópole. 0 que se pode observar, pelo mapa de 2010, é que a área dos condomínios não se classifica como um espaço Superior, mas como um espaço Superior-Médio, revelando, assim, maior mistura social ou menor segregação, do que a que se observa nas áreas centrais.

Essa constatação é confirmada pelos dados da Tabela 3, que compara as áreas de tipo Superior na capital e as de tipo Superior-Médio em Nova Lima. Tanto em números absolutos, quanto em termos relativos, as áreas centrais são as que concentram os grupos de mais alto status. $\mathrm{E}$, ainda que no interior de um condomínio possa se observar um fenômeno expressivo de autossegregação, quando se analisa uma área maior, mesmo com a forte presença de condomínios, o que se observa é a maior heterogeneidade ou mistura social. Ademais, no caso dessas áreas de ponderação, observa-se uma presença significativa de empregados 
Tabela 3 - Estrutura sócio-ocupacional nos espaços do Tipo Superior em Belo Horizonte e Tipo Superior-Médio em Nova Lima - 2010

\begin{tabular}{|c|c|c|c|c|}
\hline \multirow[t]{2}{*}{ Categorias sócio-ocupacionais } & \multicolumn{2}{|c|}{$\begin{array}{c}\text { Belo Horizonte - } \\
\text { Espaços Superiores }\end{array}$} & \multicolumn{2}{|c|}{$\begin{array}{c}\text { Nova Lima - } \\
\text { Espaços Superior-Médio }\end{array}$} \\
\hline & Num. Abs. & $\%$ & Num. Abs. & $\%$ \\
\hline Grandes Empregadores & 4.644 & 5,1 & 695 & 3,5 \\
\hline Dirigentes do Setor Público & 1.265 & 1,4 & 111 & 0,6 \\
\hline Dirigentes do Setor Privado & 2.662 & 2,9 & 334 & 1,7 \\
\hline Profissionais Autônomos de Nível Superior & 12.292 & 13,6 & 974 & 4,9 \\
\hline Profissionais Empregados de Nível Superior & 17.699 & 19,6 & 1.827 & 9,3 \\
\hline Profissionais Estatutários de Nível Superior & 4.097 & 4,5 & 430 & 2,2 \\
\hline Professores de Nível Superior & 5.746 & 6,4 & 583 & 3,0 \\
\hline Pequenos Empregadores & 3.260 & 3,6 & 492 & 2,5 \\
\hline Ocupações Artísticas, Artesãos e Similares & 1.793 & 2,0 & 239 & 1,2 \\
\hline Ocupações de Escritório & 6.640 & 7,4 & 1.429 & 7,2 \\
\hline Ocupações de Supervisão & 8.102 & 9,0 & 926 & 4,7 \\
\hline Ocupações Técnicas & 5.312 & 5,9 & 1.030 & 5,2 \\
\hline Ocupações Médias da Saúde e Educação & 2.055 & 2,3 & 527 & 2,7 \\
\hline Ocupações de Segurança Pública, Justiça e Correios & 2.368 & 2,6 & 200 & 1,0 \\
\hline Trabalhadores do Comércio & 3.145 & 3,5 & 1.479 & 7,5 \\
\hline Prestadores de Serviços Especializados & 1.386 & 1,5 & 1.076 & 5,5 \\
\hline Trabalhadores da Indústria Moderna & 258 & 0,3 & 885 & 4,5 \\
\hline Trabalhadores da Indústria Tradicional & 353 & 0,4 & 439 & 2,2 \\
\hline Operários dos Serviços Auxiliares & 415 & 0,5 & 897 & 4,5 \\
\hline Operários da Construção Civil & 991 & 1,1 & 1.633 & 8,3 \\
\hline Prestadores de Serviços Não Especializados & 601 & 0,7 & 735 & 3,7 \\
\hline Trabalhadores Domésticos & 5.049 & 5,6 & 2.499 & 12,7 \\
\hline Ambulantes e biscateiros & 171 & 0,2 & 291 & 1,5 \\
\hline Total & 90.304 & 100,0 & 19.731 & 100,0 \\
\hline
\end{tabular}

Fonte: IBGE (2011), Censo Demográfico, 2010 - dados trabalhados.

domésticos, provavelmente a parcela daqueles que moram na residência em que trabalham (5,6\% nas áreas de tipo Superior de Belo Horizonte e 12,7\% nas áreas de tipo Superior-Médio de Nova Lima). Nova Lima ainda apresenta uma porcentagem expressiva de trabalhadores da construção civil, que provavelmente moram no lugar em que trabalham, resultado de contratos de trabalho de construção por empreitada. Mendonça e Perpétuo (2006) já haviam mostrado que a realidade naquela região é bem mais complexa do que aparece no senso 
Figura 2 - Belo Horizonte

Regionais Administrativas e bairros selecionados

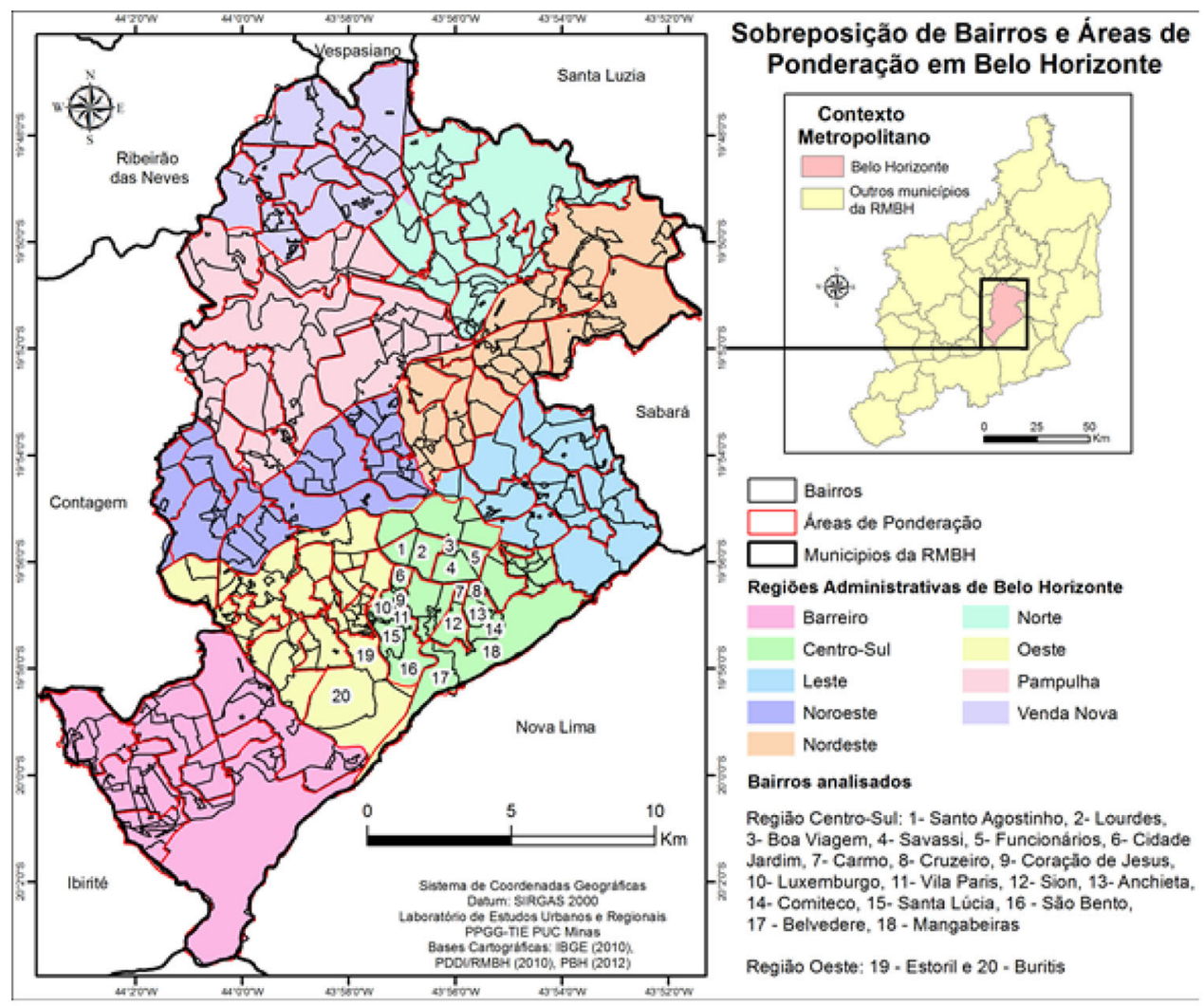

comum. A ocupação desses espaços marcada por parte das elites belo-horizontinas não constituiu homogeneidade absoluta. Ao contrário, esse processo foi acompanhado pela entrada de grupos sociais de baixa renda e baixa qualificação, configurando uma estrutura social polarizada.

Essa proximidade física de diferentes grupos sociais não significa, no entanto, menor segregação se a entendemos não apenas como a proximidade física, mas como a possibilidade de interações, de compartilhamento de espaços públicos e de instituições comuns. Mostra que, no âmbito da análise comparativa, as áreas centrais têm uma presença maior em termos absolutos e relativos (densidade) de pessoas dos estratos superiores.

Em que pese o surgimento de novas centralidades, os estudos do Observatório das Metrópoles (OM) vêm mostrando como os municípios-polo ainda concentram postos de trabalhos, serviços e melhores condições de vida. 
Os movimentos pendulares em direção ao polo e os estudos dos Índices de Bem-Estar Urbano reforçam essas tendências (Ribeiro, 2009; Ribeiro e Ribeiro, 2013). Ou seja, simultaneamente aos processos de descentralização, que não são desprezíveis, as metrópoles brasileiras conservam certos aspectos relacionados à importância econômica e social das áreas centrais, escolhidas como locais privilegiados de moradia pelos grupos de mais alto status, ainda que haja a migração de parcelas desses grupos para os condomínios localizados nas periferias metropolitanas.

As distintas formas das metrópoles, como Villaça (1998) analisou - se interioranas, como São Paulo e Belo Horizonte, com 360 graus e áreas de expansão em todas as direções; ou litorâneas, com territórios de expansão de 90 graus, como Rio de Janeiro (sem Niterói), Salvador e Porto Alegre; ou ainda de 180 graus como Recife, Fortaleza e Rio de Janeiro (com Niterói) -, influenciarão a localização dos grupos no espaço e a conformação do que chamamos aqui de área central, como explicitaremos a seguir.

A Região Metropolitana de Belo Horizonte tem como nó articulador o Centro de Belo Horizonte, lugar para o qual convergem os fluxos pendulares realizados pelo sistema de transporte público. Em torno desse Centro, estão também reunidos equipamentos hospitalares que atendem a residentes de vários municípios metropolitanos, bem como equipamentos culturais e educacionais. A região imediatamente periférica, a sul, é aquela que historicamente concentrou os grupos de maior renda, como mostra estudo da Sagmacs (1959), realizado na década de 1950 :
Na região sul da cidade, abrangendo também área interna à Av. do Contorno, toda uma zona contida pela Serra do Curral tende a se caracterizar como própria das camadas sociais superiores, separada pelo centro principal da região norte, onde se instalam as camadas inferiores. (pp. II-35)

Em consonância com o que vinha acontecendo em algumas outras metrópoles, Mendonça (2002) observou, já para os anos entre 1980 e 1990, que a metrópole belo-horizontina configurava um espaço geograficamente segregado, com a hierarquia social descendendo do centro para a periferia. Naquela década, os espaços centrais se elitizaram, e as áreas pericentrais começaram a ficar mais heterogêneas, com o espraiamento das classes médias (profissionais de nível superior e de ocupações não manuais de nível médio), alcançando, também, espaços antes tipicamente operários. Os espaços periféricos ficavam mais urbanos e, ao mesmo tempo, mais populares. Esse processo é consolidado nas décadas seguintes (Mendonça, 2008; Mendonça e Marinho, 2015), ainda que tenham surgido novas tendências de organização territorial. A concentração dos grupos superiores nos espaços centrais segue, crescentemente intensificada, configurando a hipersegregação.

Algumas hipóteses podem ser arroladas para explicar o fenômeno da hipersegregação. Em primeiro lugar, a concentração do segmento de mercado de imóveis de alto luxo nessas áreas centrais, já anteriormente ocupadas pelos grupos de alto status. Em segundo lugar, as políticas urbanas que historicamente levaram à concentração de melhor infraestrutura e de bens raros, como as instituições culturais e as 
chamadas amenidades urbanas nessas áreas, tornando-as mais exclusivas, dado os serviços que oferecem e a concentração de bens raros, como o patrimônio cultural da cidade, museus, teatros, comércio, serviços e restaurantes sofisticados. Ambos os fatores contribuíram para a saída de grupos com menor status, o que acabou também contribuindo para a maior densidade dos grupos superiores nessas áreas. Soma-se, a isso, a oferta de imóveis nas periferias metropolitanas para os grupos de médio status, o que atuou como atrativo para que esses grupos médios trocassem as áreas centrais por novos imóveis nas áreas periféricas.

As evidências empíricas para o exame dessas hipóteses serão analisadas em dois recortes espaciais:

- Região Administrativa ${ }^{12}$ Centro-Sul, que congrega, além do bairro Centro, os bairros residenciais mais afluentes, mencionados por Sagmacs (1959), no entorno sul do Centro, e que se expande até os limites da Serra do Curral e do município de Nova Lima, ${ }^{13}$ sendo caracterizada por intensa verticalidade, forte concentração de atividades econômicas e alto padrão de ocupação; e

- Conjunto de bairros que concentram os estratos sócio-ocupacionais superiores: Anchieta, Belvedere, Boa Viagem, Buritis, Carmo, Cidade Jardim, Comiteco, Coração de Jesus, Cruzeiro, Estoril, Funcionários, Lourdes, Luxemburgo, Mangabeiras, Santa Lúcia, Santo Agostinho, São Bento, Savassi, Sion e Vila Paris.

Ambos os recortes se encontram identificados na Figura 2, que também traz o desenho das áreas de ponderação, de modo a permitir o cruzamento com as informações presentes na Figura 1.
Para tratar do mercado imobiliário, vamos utilizar, aqui, os dados dos registros de novas construções de apartamentos do Cadastro Imobiliário da Prefeitura de Belo Horizonte (PBH). ${ }^{14}$ Ainda que tais dados inexistam para 0 restante da $\mathrm{RMBH}$, as áreas dos estratos superiores, foco deste artigo, estão todas concentradas na cidade de Belo Horizonte.

A PBH classifica os imóveis do tipo apartamento, que caracterizam mais de $50 \%$ das moradias dos grupos superiores, numa hierarquia que vai de P1, o tipo mais simples, até P5, o mais sofisticado. Essa classificação leva em conta diversas características construtivas do imóvel e define o valor do metro quadrado da construção que será utilizado no cálculo do valor do imóvel, para fins de cobrança dos tributos imobiliários. Uma vez que estamos procurando compreender as mudanças que se processaram nas áreas dos estratos superiores, vamos trabalhar aqui com o padrão mais alto de apartamento, o P5.

Entre 2000 e 2010, foram construídos, em Belo Horizonte, 78.795 novos apartamentos. Destes, 4.417 foram classificados como P5, ou seja, 5,6\%. Na década anterior, 1990-2000, haviam sido construídos 67.245. Destes, 2.519 foram classificados como P5, ou seja, 3,7\%. Esses dados mostram tanto um aumento no número de apartamentos construídos, quanto na proporção de apartamentos de padrão mais alto, o P5. No entanto, a oferta dessas unidades de padrão mais elevado encontra-se altamente concentrada na regional Centro-Sul (Figura 3), uma área historicamente marcada pela forte presença de grupos sociais de alto status, fato que corrobora a primeira hipótese sobre as razões da hipersegregação das classes superiores. 
Figura 3 - Quantidade de novos apartamentos, por padrão de acabamento Regiões Administrativas de Belo Horizonte: 2000-2010

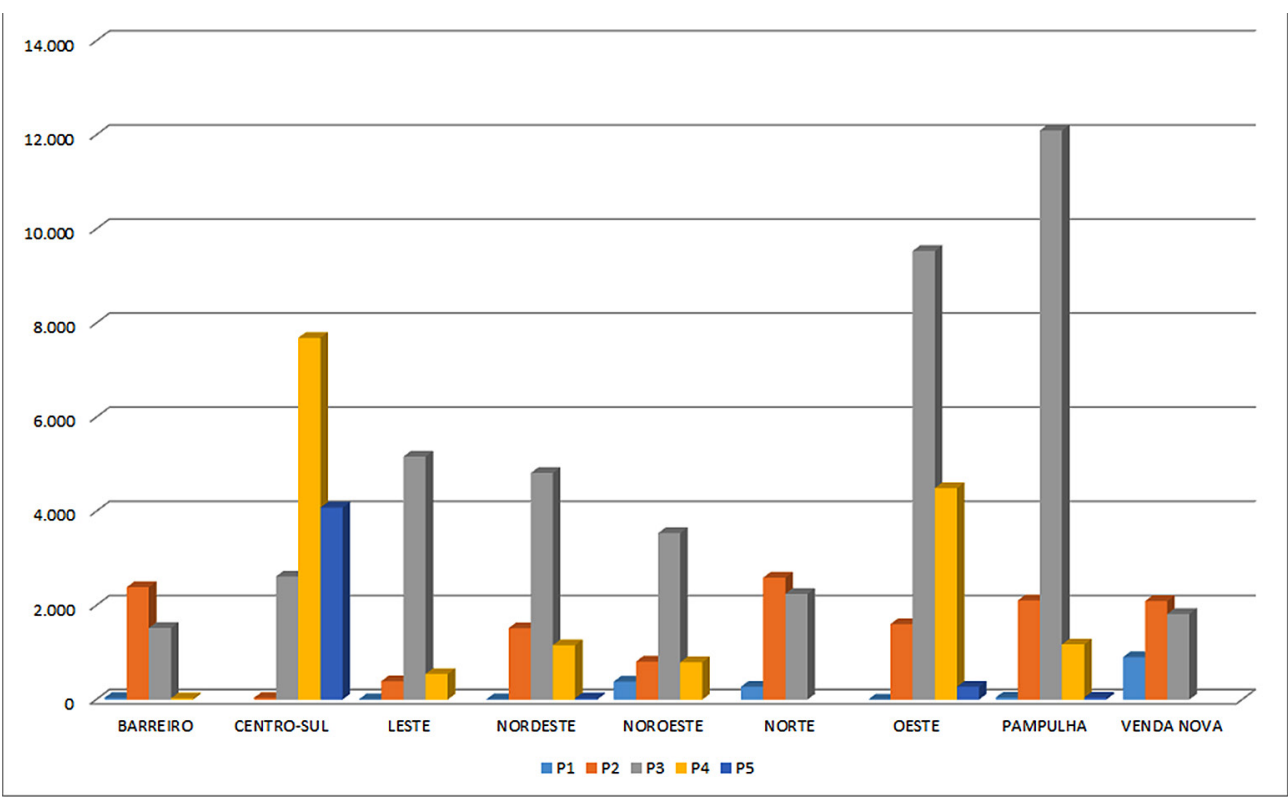

Fonte: Cadastro Imobiliário da Prefeitura de Belo Horizonte.

Quando analisamos o conjunto de bairros dos estratos superiores (ver Figura 2), chegamos aos seguintes resultados: foram construídos 18.446 novos apartamentos, entre os quais 3.387 eram P5, ou seja, 18,4\%. 0 que esses dados mostram é que a concentração desse tipo de apartamento nos bairros dos estratos superiores é mais que o triplo da média da cidade $(5,6 \%)$.

A Figura 4 detalha a oferta de novos apartamentos nos bairros dos estratos superiores, segmentados por padrão de acabamento. 0 primeiro aspecto que chama a atenção é a significativa oferta de novas unidades no bairro Buritis, de padrão médio e alto, que ultrapassa a soma dos demais bairros listados. Trata-se de um bairro mais recente, que se encontra na regional Oeste, cuja evolução ocorreu pela combinação da disponibilidade de terrenos vagos, alto potencial de aproveitamento do solo até julho de 2010 , bem como por sua a posição geográfica estratégica. 0 bairro é popularmente conhecido por abrigar os filhos das famílias da Centro-Sul, e hoje conta com uma população próxima a 30 mil habitantes. Outro aspecto que chama a atenção é a maior oferta de novos apartamentos de padrão luxo (P5) nos bairros Anchieta, Funcionários, Lourdes, Santo Agostinho, Savassi e Sion (Figura 4). Alguns bairros dessa região, como Cidade 
Jardim, Mangabeiras e Comiteco, assim como parte do Belvedere, têm legislações restritivas para construção de edifícios. De todo modo, a maior ou menor presença de edifícios do tipo P5 tem relação com as estratégias do mercado imobiliário de criar localizações de prestígio e alto valor simbólico.

Destaque-se que o conjunto desses bairros possui certa heterogeneidade interna. Alguns são mais elitizados do que outros, o que se reflete na área dos apartamentos construídos. Em se tratando de apartamentos do tipo
P5, a área é bastante generosa. A menor média de área no período em estudo foi encontrada na Vila Paris, $270 \mathrm{~m}^{2}$, e a maior no Belvedere, $464 \mathrm{~m}^{2}$.

Como mencionado, as políticas urbanas que levaram à concentração de melhor infraestrutura e de bens raros como as instituições culturais e as chamadas amenidades urbanas na região Centro-Sul, na qual residem os estratos superiores, constitui importante fator de atração do capital imobiliário para essas áreas. Há que ressaltar, ainda, a proximidade dos

Figura 4 - Quantidade de novos apartamentos, por padrão de acabamento Bairros selecionados de Belo Horizonte: 2000-2010

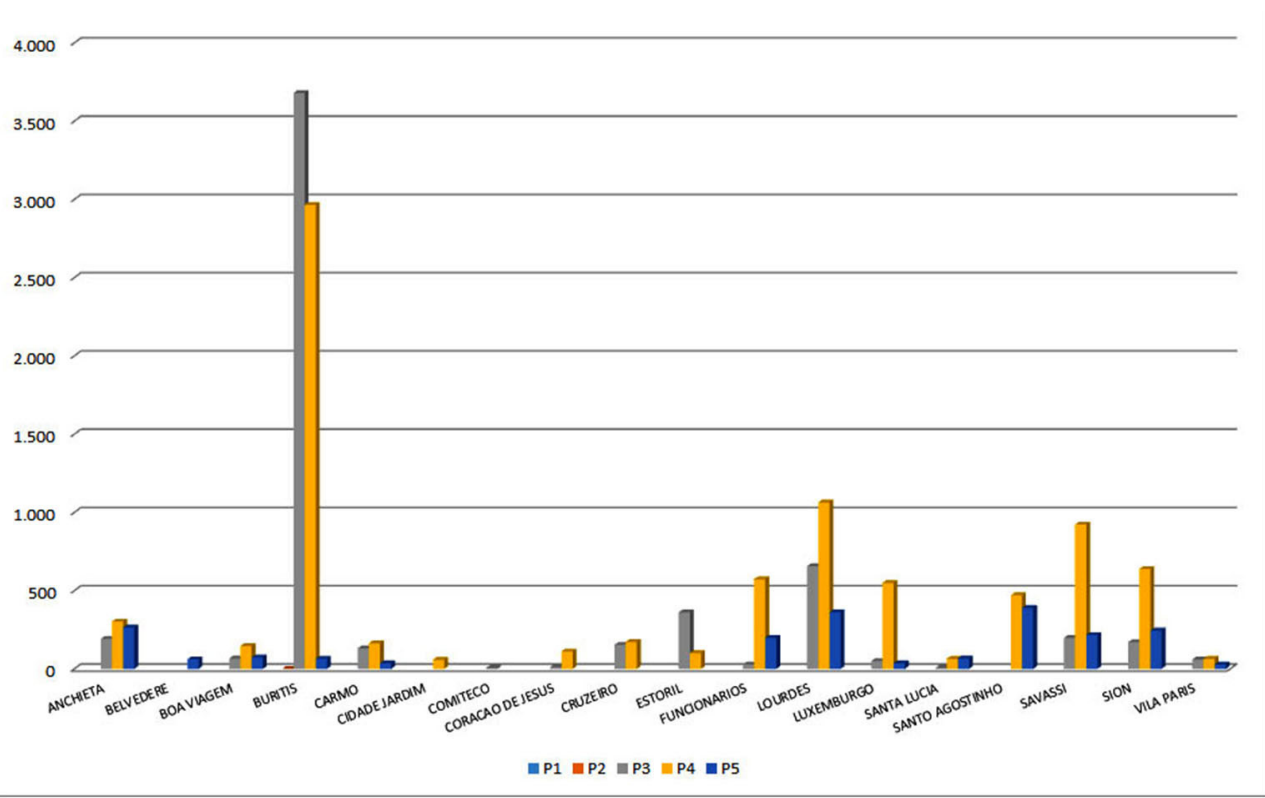

Fonte: Cadastro Imobiliário da Prefeitura de Belo Horizonte. 
bairros dos estratos superiores com o centro histórico, que reúne o patrimônio cultural da cidade, além de importantes espaços públicos de lazer, mas também de realização de festas e manifestações políticas -, instituições culturais, assim como instituições públicas e privadas de grande importância. Além disso, a área central compreende duas outras novas centralidades, que convivem com a do Centro histórico tradicional. A primeira delas, a da Savassi, surgiu na década de 1970, quando o Centro histórico dava os primeiros sinais de obsolescência. $A$ segunda surgiu nos anos de 1980, na fronteira com o município de Nova Lima, no qual hoje existem vários condomínios. Seu equipamento mais importante é o BH Shopping, o primeiro shopping center da cidade, inaugurado em 1979, quando, ao seu redor, não havia muitas construções. Hoje o seu entorno é lugar de moradia dos estratos superiores e configura centro de comércio, serviços e lazer.

Apesar dos esforços despendidos pela municipalidade, a partir da década de 1990, no sentido de descentralizar a cultura, com a criação de vários centros culturais nos distintos espaços da cidade e de programas culturais voltados para as áreas periféricas, na última década (2000-2010) foram inaugurados vários museus e centros culturais que compõem o Circuito Cultural Praça da Liberdade na área central da cidade. Reunidos em um só espaço, o entorno da Praça da Liberdade, na qual se localiza a antiga sede do governo estadual, destacando-se o Centro Cultural Banco do Brasil, com mostras regulares de arte do Brasil e do exterior.

Em "Efeitos do lugar", Bourdieu (1997) trata dos benefícios do espaço social reificado, tais como os ganhos de localização, com as rendas associadas a proximidades com bens raros e cobiçados, como equipamentos educacionais, culturais e de saúde. Já os ganhos de posição ou de classe estão ligados à posse de um endereço prestigioso; e os ganhos de ocupação traduzem-se na posse de um espaço físico como grandes apartamentos, grandes áreas como forma de manter a distância coisas e pessoas indesejáveis. Clark et al. (2002) tratam das amenidades urbanas, que vão além das escolas, igrejas e associações de bairro priorizadas pela Escola de Chicago. Os grupos urbanos com renda e nível educacional alto procuram espaços com maiores possibilidades de consumo e lazer, aspectos que se juntam à qualidade da moradia e que não estão igualmente distribuídos em todo o território de uma cidade, mas se encontram muito concentrados em algumas poucas áreas. Junto com a moradia, as amenidades constituem importantes elementos dos estilos de vida dessa população urbana, como atesta Clark et al: "provision of lifestyle amenities has become a key feature of urban development that we must recognize conceptually" (ibid., p. 500).

No Brasil, não temos ainda estudos que foquem esses temas abordados tanto por Bourdieu quanto por Clark et al. e suas relações com o estilo de vida dos grupos de alta renda. Mediações, como entre os yuppies americanos (uma das referências de estudos como o que citamos, mas também dos estudos sobre gentrificação) e os ricos brasileiros, precisariam ser objeto de pesquisas. A segurança, por exemplo, é uma amenidade citada nos estudos americanos, mas que, no Brasil, tem um lugar ainda mais proeminente. De toda forma, essas análises são importantes ao chamar a atenção para aspectos 
de localização nem sempre levados em consideração, até porque pouco mensuráveis por meio de instrumentos e bases de dados tradicionais da pesquisa urbana.

Esses aspectos ficam evidentes no exame do Índice de Qualidade de Vida ${ }^{16}$ e de alguns de seus indicadores (ver as Figuras 5 a 10). Note-se como a Região Administrativa Centro Sul é aquela que congrega os mais altos níveis de qualidade de vida do município, de forma consistente na quase totalidade das suas Unidades de Planejamento (UP), ${ }^{17}$ exceto na UP correlata ao aglomerado subnormal (Cafezal) (Figura 5). A região em que se manifesta a hipersegregação dos segmentos superiores também apresenta a maior proporção per capita de equipamentos de saúde, hiper e supermercados, agências bancárias, farmácias, equipamentos culturais e livrarias (Figuras 6, 7, 8, 9 e 10), confirmando o magnetismo exercido pelos "Efeitos do lugar" (Bourdieu, 1997) nos membros desse segmento social.

Figura 5 - Índice de qualidade de vida urbana Regionais administrativas de Belo Horizonte - 2014

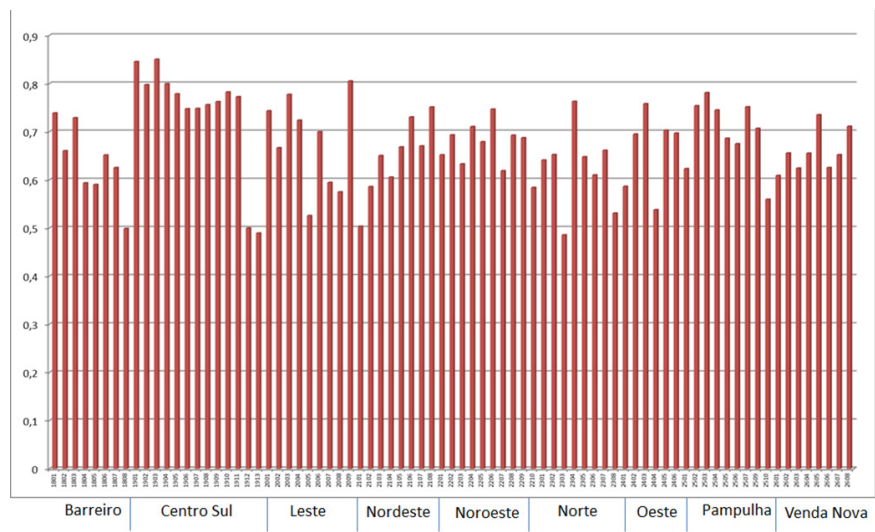

Figura 6 - Equipamentos de saúde / 1.000 hab. Regionais administrativas de Belo Horizonte - 2014

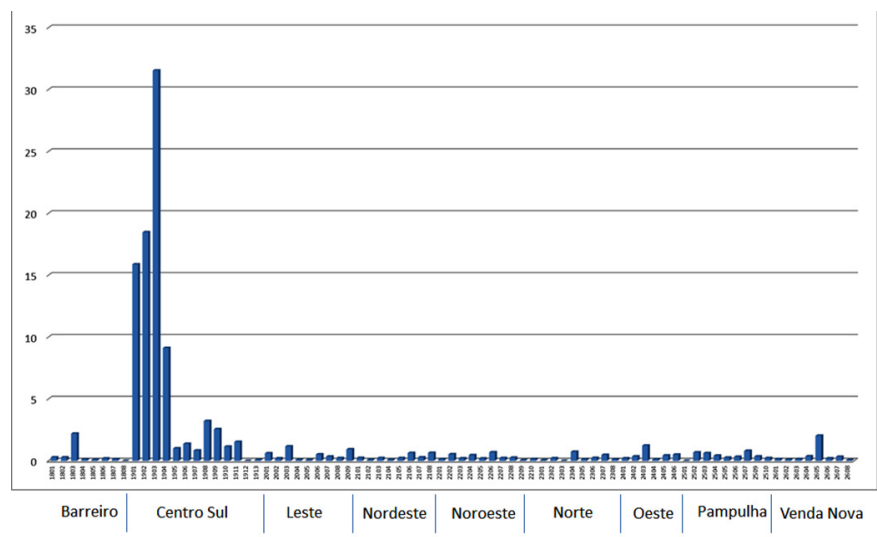


Figura 7 - Número de hiper e supermercados por mil habitantes Regionais administrativas de Belo Horizonte - 2014

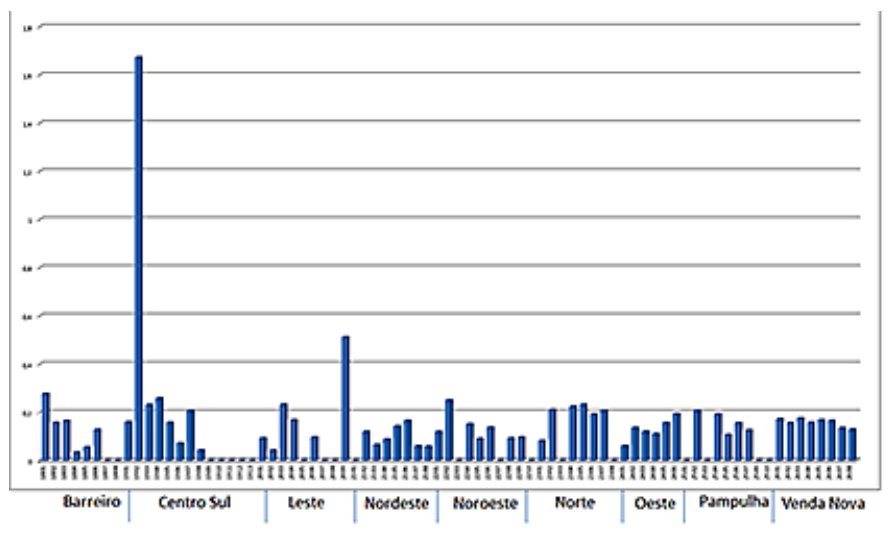

Figura 8 - Agências bancárias e farmácias / 1.000 hab Regionais administrativas de Belo Horizonte - 2014

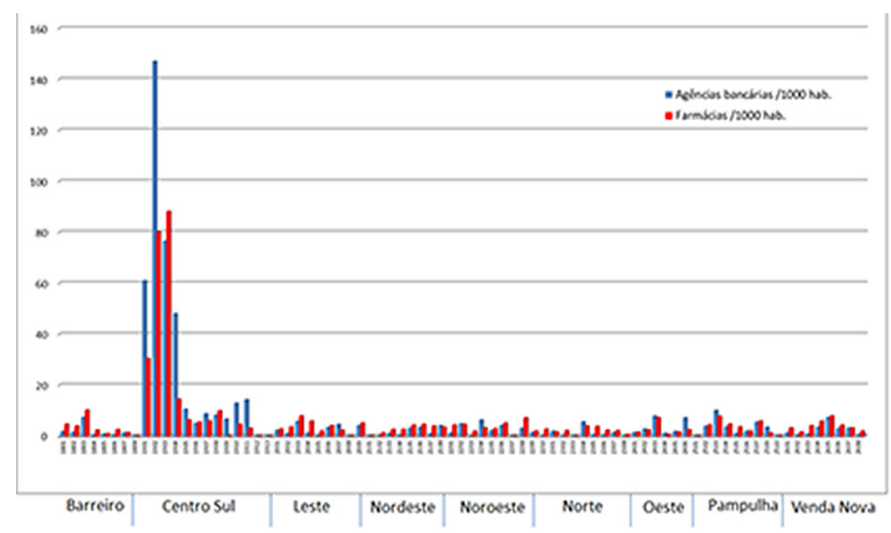


Figura 9 - Número de equipamentos culturais por mil habitantes

Regionais administrativas de Belo Horizonte - 2014

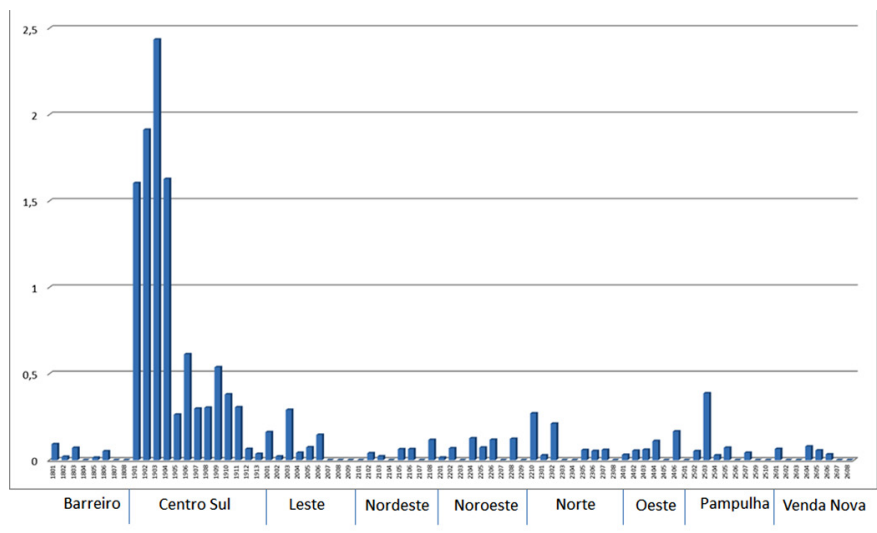

Figura 10 - Livrarias e papelarias ( $\mathrm{m}^{2} / \mathrm{hab}$.)

Regionais administrativas de Belo Horizonte - 2014

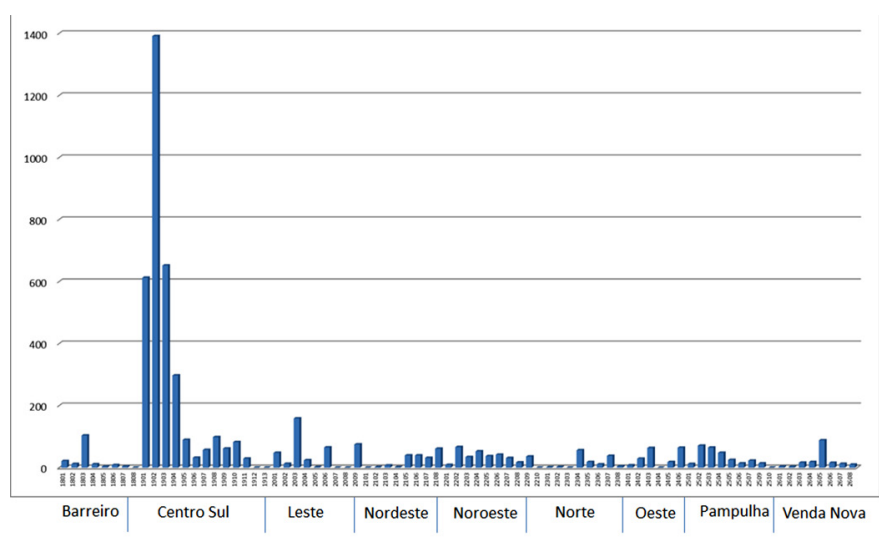




\section{Considerações finais}

0 estudo da estrutura socioespacial das principais metrópoles brasileiras na década de 2000 mostrou que, ao lado da maior complexidade e heterogeneidade social no território, os grupos superiores na hierarquia social mostraram-se mais concentrados nas áreas classificadas como de Tipo Superior, as quais estão localizadas nas áreas centrais - apenas a Região Metrropolitana de São Paulo tem espaço superior fora do núcleo.

A análise específica da Região Metropolitana de Belo Horizonte, metrópole que tem composição social muito semelhante à média das 15 metrópoles estudadas, evidenciou o impacto da formação histórica da área central sobre a dinâmica imobiliária e a atratividade que essa área tem para os grupos superiores na hierarquia social. Se, por um lado, o histórico padrão centro-periférico de organização das metrópoles tornou-se mais complexo, com o surgimento de enclaves residenciais e novas centralidades nas periferias, por outro, o polo e suas áreas centrais ainda se configuram como os espaços de representação simbólica de poder e prestígio. Nesse contexto, o centro histórico, ainda que submetido ao que os economistas denominam economias de desaglomeração, devido principalmente aos problemas de trânsito e poluição, permanece o espaço no qual estão concentrados os bens raros - museus, teatros e outros serviços - e em torno do qual gravitam bairros em que se concentraram os grupos superiores, por nós denominamos área central. Os dados para Belo Horizonte mostram, ainda, que a representação simbólica dessa área, sustentada pela concentração de bens raros e das amenidades urbanas, coloca-a como localização preferencial dos investimentos imobiliários de alto padrão, consolidando o fenômeno da hipersegregação das elites.

\section{[I] https://orcid.org/0000-0001-9716-7832}

Universidade Federal de Minas Gerais, Faculdade de Arquitetura e Urbanismo, Programa de Pós-Graduação em Arquitetura e Urbanismo. Belo Horizonte, MG/Brasil.

jupira@gmail.com

\section{[II] https://orcid.org/0000-0001-6137-1268}

Pontifícia Universidade Católica de Minas Gerais, Departamento de Ciências Sociais, Programa de Pós-Graduação em Ciências Sociais. Belo Horizonte, MG/Brasil.

lucianatandrade1@gmail.com

\section{[III] https://orcid.org/0000-0002-5649-7736}

Pontifícia Universidade Católica de Minas Gerais, Instituto de Ciências Humanas, Programa de Pós-Graduação em Geografia. Belo Horizonte, MG/Brasil.

alexandremadiniz@gmail.com 


\section{Notas}

(1) Para mais detalhes sobre esses procedimentos, ver Mendonça (2002).

(2) Ver as coletâneas publicadas em 2015, denominadas Transformações na ordem urbana. Disponíveis em: www.observatoriodasmetropoles.net/.

(3) Em 2009, o Observatório das Metrópoles (OM) realizou um estudo com o objetivo de identificar, entre o conjunto das regiões metropolitanas institucionalizadas, quais eram efetivamente metropolitanas, chegando a um conjunto de 15 RM: Belém, Belo Horizonte, Campinas, Curitiba, Florianópolis, Fortaleza, Goiânia, Manaus, Porto Alegre, Recife, Rio de Janeiro, Salvador, São Paulo, Vitória e a Área Metropolitana de Brasília (Ribeiro, 2009).

(4) O IBGE adota, como referência para a contabilização dos censos demográficos, dois questionários, sendo um mais detalhado e extenso, aplicado a uma amostra de domicílios, e outro menos complexo, aplicado aos domicílios não selecionados para a amostra. Por isso, os dados censitários encontram-se disponíveis em duas unidades espaciais: "áreas de ponderação", com os resultados do questionário detalhado, e "setores censitários", com os resultados do questionário simples (IBGE, 2003 e 2011). A utilização aqui dos dados por área de ponderação se relaciona ao fato de que somente nessa unidade, e como resultado do questionário complexo, se tem acesso à variável ocupação. Em relação aos estudos qualitativos, que em geral escolhem como unidade de análise os bairros, ou até mesmo unidades menores, é importante registrar que a área de ponderação é bem maior que o bairro, na verdade ela engloba um conjunto de bairros. Seu tamanho tem relação direta com a representatividade estatística dos dados.

(5) Em função das flutuações populacionais ocorridas no âmbito dos municípios no período de um censo para outro, algumas dessas unidades territoriais precisam ser redefinidas, razão pela qual elas não podem ser diretamente comparadas (Umbelino e Barbieri, 2016).

(6) Em algumas RM, essa proporção é um pouco maior, com destaque para as RMs Manaus $(7,0 \%$ em 2000 e 6,5\% em 2010) e Curitiba (4,7\% em 2000 e 4,5\% em 2010).

(7) As denominações dos tipos espaciais procuram destacar a predominância de um grupo em relação aos outros. Assim, Superior significa a predominância desse grupo no espaço, Superior-Médio a predominância desses dois grupos, na ordem como são apresentados, primeiro superior e, em seguida, médio, e assim com todos os outros. Já as denominações Heterogêneo-Superior e Heterogêneo-Inferior se fizeram necessárias para dar conta de um fenômeno novo, qual seja, o da mistura, sem uma predominância clara de um grupo específico.

(8) As exceções são as ocupações artísticas, artesãos e similares e as ocupações de supervisão que apresentaram crescimento.

(9) O Quociente Locacional compara a participação percentual de cada categoria sócio-ocupacional em cada típico específico em relação à sua participação no conjunto da população ocupada naquele tipo, somando-se todas as regiões metropolitanas estudadas. 0 quociente igual a 1 significa uma participação da categoria sócio-ocupacional igual a sua participação no conjunto da população ocupada das metrópoles estudadas. Quanto maior que 1, maior é a concentração da categoria em determinado tipo, e quanto menor que 1, mais sub-representada está a categoria.

(10) Pesquisa realizada na RMBH pela Agência de Desenvolvimento, em 2012. 
(11) A pesquisa de Origem e Destino traz dados de renda e de educação das pessoas que se mudaram. A opção por usar a renda deveu-se ao fato da maior qualidade desse dado, no que se refere ao número de respostas, em relação à renda. Este último quesito não foi respondido por muitos dos entrevistados.

(12) A lei municipal n. 10.231, de 19 de julho de 2011, organiza o município de Belo Horizonte para gestão do território em nove regiões administrativas: Barreiro, Centro-Sul, Leste, Nordeste, Noroeste, Norte, Venda Nova, Pampulha e Oeste.

(13) Tomando como referência as dinâmicas das décadas de 1980 e 1990, Teixeira e Souza (2003) definiram essa área como Núcleo Central da seguinte forma: “[...] é o espaço de morada da elite dirigente, da pequena burguesia e da chamada elite intelectual em proporções crescentes, tanto em 1980 quanto em 1991. Acolhe também um grande contingente de profissionais das classes médias e do subproletariado, mas em proporções decrescentes; não é o local de residência do proletariado do terciário e principalmente do secundário, bem como do pessoal ligado às atividades agrícolas" (p. 35).

(14) Os autores agradecem, à Prefeitura de Belo Horizonte, a disponibilização dos dados. Agradecem, também, a Sérgio Moraleida, a inestimável ajuda na compreensão desses dados. As análises, como de praxe, são da inteira responsabilidade dos autores.

(15) Os bairros Santa Lucia e Mangabeiras não tiveram novas unidades de apartamento no período em questão.

(16) O Índice de Qualidade de Vida Urbana de Belo Horizonte (IQVU-BH) quantifica a disponibilidade e o acesso a bens e serviços urbanos, avaliando o nível da infraestrutura de serviços urbanos disponíveis no município. O IQVU-BH é calculado para 79 divisões intraurbanas denominadas Unidades de Planejamento (UP), sendo composto por dez variáveis, resultantes da agregação de 33 indicadores, às quais se atribuem pesos diferentes ( $\mathrm{PBH}, 2015)$.

(17) Divisões espaciais do município de Belo Horizonte, criadas pela prefeitura para auxiliar no planejamento e gestão urbanos.

\section{Referências}

BOURDIEU, P. (1997). “Efeitos de lugar”. In: BOURDIEU, P. (org.). A miséria do mundo. Petrópolis, Vozes.

CALDEIRA, T. P. do R. (2000). Cidade de muros: crime, segregação e cidadania em São Paulo. São Paulo, Editora 34 e Edusp.

CLARK, T. N. et al. (2002). Amenities drive urban growth. Journal of urban affairs, v. 24, n. 5, pp. 493-515.

CORTEZ, B. F.; MONTENEGRO, F. M. T. e BRITO, J. A. M. (2012). Censo Demográfico 2010 - definição das áreas de ponderação para o cálculo das estimativas provenientes do questionário da amostra. In: XVIII ENCONTRO NACIONAL DE ESTUdOS POPULACIONAIS. Anais. Águas de Lindóia, pp. 1-13. 
DINIZ, A. M. A.; ANDRADE, L. T. de e MENDONÇA, J. G. de M. (2018). La estructura socio-ocupacional metropolitana brasileña: diversificación y homogeneidad en la década de 2000. Belo Horizonte, mimeo.

HARVEY, D. (1977). Urbanismo y desigualdad social. México D.F., Madrid, Bogotá, Siglo XXI.

IBGE (2003). Censo demográfico 2000. Agregado por setores censitários dos resultados do universo. Rio de Janeiro, Documentação do Arquivo.

(2011). Censo demográfico 2010: resultados preliminares da amostra. Rio de Janeiro, IBGE. Disponível em: <https://ww2.ibge.gov.br/home/estatistica/populacao/censo2010/resultados_ preliminares_amostra/notas_resultados_preliminares_amostra.pdf>. Acesso em: 15 set 2018.

LAGO, L. C. do (2011). Autogestão da moradia na superação da periferia urbana: conflitos e avanços. E-metropolis: Revista Eletrônica de Estudos Urbanos e Regionais. Rio de Janeiro, v. 5, pp. 6-12.

LAGO, L. C. do e MAMMARELLA, R. (2010). Da hierarquia de classes à organização social do espaço intraurbano: um olhar comparativo sobre as grandes metrópoles brasileiras. Cadernos Metrópole. São Paulo, v. 12, n. 23, pp. 65-84.

LEFEBVRE, H. (1969). O direito à cidade. São Paulo, Editora Documentos.

MACEDO, D. R. e UMBELINO, G. (2016). Análise espacial da evolução da urbanização em Belo Horizonte (1918-2010) e suas relações com os indicadores de renda e estrutura etária nos Censos de 2000 e 2010. In: XX ENCONTRO NACIONAL DE ESTUDOS POPULACIONAIS. Anais. Foz do Iguaçu, pp.1-16.

MASSEY, D. S. e DENTON, N. A. (1989). Hypersegregation in US metropolitan areas: Black and Hispanic segregation along five dimensions. Demography, v. 26, n. 3, pp. 373-391.

MENDONÇA, J. G. de (2002). Segregação e mobilidade residencial na Região Metropolitana de Belo Horizonte. Tese de doutorado. Rio de Janeiro, Ippur/UFRJ.

(2008). “Estrutura socioespacial da RMBH nos anos 2000: há algo de novo?” In: ANDRADE, L. T.; MENDONÇA, J. G. e FARIA, C. A. P. Metrópole: território, sociedade e política - o caso da Região Metropolitana de Belo Horizonte. Belo Horizonte, PUC Minas.

MENDONÇA, J. G. de e MARINHO, M. A. C. (2015). “As transformações socioespaciais na Região Metropolitana de Belo Horizonte". In: ANDRADE, L. T.; MENDONÇA, J. G. e DINIZ, A. M. A. Belo Horizonte: transformações na ordem urbana. Rio de Janeiro, Letra Capital/Observatório das Metrópoles/Belo Horizonte, PUC-Minas.

MENDONÇA, J. G. e PERPÉTUO, I. H. O. (2006). “A metrópole belo-horizontina em expansão: periferização da riqueza ou polarização social?”. In: COSTA, H. S. M.; COSTA, G. M.; MENDONÇA, J. G. e MONTE-MÓR, R. L. M. Novas periferias metropolitanas: a expansão metropolitana em Belo Horizonte: dinâmica e especificidades no Eixo Sul. Belo Horizonte, Editora C/Arte.

MENDONÇA, J. G. e COSTA, H. S. M. (2011). “Dinâmica imobiliária e a formação de um obscuro objeto de desejo: localização residencial e representação simbólica". In: MENDONÇA, J. G. e COSTA, H. S. M. (orgs.). Estado e capital imobiliário: convergências atuais na produção do espaço urbano brasileiro. Belo Horizonte, C/Arte.

PBH - PREFEITURA MUNICIPAL DE BELO HORIZONTE (2015). Relatório geral sobre o cálculo do índice de qualidade de vida urbana de Belo Horizonte (IQVU-BH) para 2014: Série histórica e nova série.

RIBEIRO, L. C. (2002). Segregação, acumulação urbana e poder: classes e desigualdades na metrópole do Rio de Janeiro. Cadernos IPPUR. Rio de Janeiro, v. 16, n. 1, pp. 79-103. 
RIBEIRO, L. C. Q. (2003). “Segregação residencial e políticas públicas: análise do espaço social da cidade na gestão do território". In: NETO, E. R. e BÓGUS, C. M. (orgs.). Saúde nos aglomerados urbanos: uma visão integrada. Brasília, Organização Pan-Americana da Saúde.

(org.) (2009). Hierarquização e identificação dos espaços urbanos. Série Conjuntura Urbana. v. 1. Rio de Janeiro, Letra Capital/Observatório das Metrópoles.

RIBEIRO, L. C. de Q. e LAGO, L. C. do (1992). “Crise e mudança nas metrópoles brasileiras: a periferização em questão". In: LEAL, M. C. et al. (orgs.). Saúde, ambiente e desenvolvimento: uma análise interdisciplinar. São Paulo, Hucitec / Rio de Janeiro, Abrasco.

RIBEIRO, L. C. de Q. e RIBEIRO, M. G. (orgs.) (2013). IBEU - Índice de bem-estar urbano. Rio de Janeiro, Letra Capital.

RIBEIRO, M. G.; COSTA, L. G. e RIBEIRO, L. C. de Q. (2013). Estrutura social das metrópoles brasileiras: análise da primeira década do século XXI. Rio de Janeiro, Letra Capital.

SAGMACS (1959). Estrutura urbana de Belo Horizonte. Belo Horizonte, Prefeitura de Belo Horizonte.

TEIXEIRA, J. G. e SOUZA, J. M. de (2003). "Espaço e sociedade na Grande BH”. In: MENDONÇA, J. G. de e GODINHO, M. H. L. (orgs.). População, espaço e gestão na metrópole: novas configurações, velhas desigualdades. Belo Horizonte, PUC Minas.

UMBELINO, G. e BARBIERI, A. (2016). Metodologia para a compatibilização de setores censitários e perímetros urbanos entre os censos de 1991, 2000 e 2010. XVI ENCONTRO NACIONAL DE ESTUDOS POPULACIONAIS. Anais. Caxambu, APEB, pp. 1-18.

VILLAÇA, F. (1998). Espaço intra-urbano no Brasil. São Paulo, Studio Nobel.

Texto recebido em 18/out/2018

Texto aprovado em 24/nov/2018 